\title{
Satisfaction in Interpersonal Interactions as a Function of Similarity in Level of Dysphoria
}

\author{
Kenneth D. Locke and Leonard M. Horowitz \\ Stanford University
}

\begin{abstract}
This study compared dysphoric and nondysphoric male and female undergraduates as they conversed with dysphoric or nondysphoric undergraduates of the same sex. Subjects rated their satisfaction with the conversation after each turn. The results showed that people in homogeneous dyads (i.e., both partners were dysphoric or both partners were nondysphoric) were more satisfied with the interaction, and their satisfaction increased as the conversation proceeded. People in mixed dyads were less satisfied, perceived each other as colder, and spoke about increasingly negative topics. Thus, in accord with other research showing that similarity leads to liking, the crucial determinant of interactional satisfaction was neither the mood of the subject nor the mood of the partner, but their similarity in mood.
\end{abstract}

Dysphoria is a state of mild depression that most people experience from time to time. Dysphoria and interpersonal interactions may have a reciprocal effect on each other, and both may be important for an individual's sense of well-being (Coates \& Winston, 1983; Horowitz \& Vitkus, 1986); it is therefore important to understand how dysphoria and interpersonal interactions affect each other. This article examines how the level of dysphoria of two interacting individuals influences their satisfaction with the interaction and their evaluations of one another.

Previous research relating negative moods to interpersonal relations has focused on more severe depressions. Typically, in these studies subjects were exposed to persons who were or were not exhibiting signs of depression, and various reactions to the target person were assessed. These studies have indicated that people find interactions with depressed people to be aversive. This result has been observed in a variety of experimental contexts. In some studies, subjects conversed with outpatients over a telephone (Coyne, 1976a) or listened to audiotapes of inpatients (Boswell \& Murray, 1981); in other studies, subjects watched videotapes of a dissimulator (Amstutz \& Kaplan, 1987; Gurtman, 1987) or interacted with a dissimulator (Hammen \& Peters, 1978; Howes \& Hokanson, 1979; Marks \& Hammen, 1982; Stephens, Hokanson, \& Welker, 1987); in still others, subjects read transcripts describing hypothetical persons (Gotlib \& Beatty, 1985; Hammen \& Peters, 1977; Winer, Bonner, Blaney, \& Murray, 1981).

The research reported in this article was supported by a National Science Foundation Award to Kenneth D. Locke and by Grant R01 MH 40417 of the National Institute of Mental Health to Leonard M. Horowitz.

We are grateful to Derek Kober, Kathryn Lee, and Peter Olson for their help in coding the interactions.

Correspondence concerning this article should be addressed to Kenneth D. Locke, who is now at the Division of Natural Sciences, State University of New York, Purchase, New York 10577, or to Leonard M. Horowitz, Department of Psychology, Jordan Hall, Stanford University, Stanford, California 94305.
Two studies compared nondepressed students interacting face-to-face with depressed or nondepressed students in a 15min "get acquainted" conversation (Gotlib \& Robinson, 1982; Strack \& Coyne, 1983). One found that the nondepressed subjects who had talked with depressed people came to feel more hostile, depressed, anxious, and less willing to interact with their partner in the future (Strack \& Coyne, 1983). The other study reported that nondepressed subjects interacting with depressed people smiled less, exhibited less pleasant facial expressions, fidgeted more, talked more about negative topics, and used a more monotonous tone of voice. These differences were apparent to observers within the first $3 \mathrm{~min}$ of the exchange (Gotlib \& Robinson, 1982).

Although these studies demonstrated that subjects generally react less favorably to depressed targets than to nondepressed targets, they did not distinguish between the reactions of depressed and nondepressed subjects. Interestingly, the few studies that did examine this variable showed a weaker or reversed pattern for depressed subjects. Most of these studies examined reactions to hypothetical target persons. In one such study (Rosenblatt \& Greenberg, 1988), depressed and nondepressed subjects were presented with hypothetical responses of a depressed or nondepressed target on the Beck Depression Inventory. Whereas nondepressed subjects preferred nondepressed targets, depressed subjects did not differ in their reactions to the two types of targets. Bell (1978) induced mildly positive or negative moods and then had subjects rate their reactions to a hypothetical target person who was feeling happy, neutral, or unhappy. The results indicated that the sad subjects were more interested than the happy subjects in working with the unhappy target. Similarly, Wenzlaff and Prohaska (1989) found that both depressed and nondepressed subjects preferred to meet subjects who were in a mood similar to their own (if the event causing the other person's mood was attributable to luck). A fourth study (Gibbons, 1986) found that following a worsening of their moods, depressed college students preferred to read descriptions of life events written by individuals also experiencing negative moods. Finally, in a study involving actual face-toface interactions, Strack and Coyne (1983) found that depressed 
subjects were less interested than nondepressed subjects in future interactions with a nondepressed partner. This study did not examine the reactions of depressed subjects to a depressed partner.

These findings are in accord with a large body of literature showing positive relationships between attitude similarity and interpersonal attraction (Byrne, 1971). For example, a naturalistic study by Newcomb (1961) showed that the similarity between people's attitudes before meeting is predictive of their subsequent attraction to each other. Dozens of laboratory studies have also found that subjects are more attracted to people they believe to be attitudinally similar to themselves (Byrne, 1971). There is also some evidence that similarity in personality predicts initial attraction (although the results of these studies are less consistent). For example, Duck (1973) had female strangers (a) complete the California Personality Inventory (CPI; Gough, 1964), (b) discuss important social issues in small groups, and then (c) record the names of the group members to whom they were attracted. The results showed that subjects who were similar in their self-ratings on the CPI were more attracted to one another.

No study, however, has examined the impact of mood similarity on actual face-to-face interactions. Moreover, the literature has focused on the impact of depression, not on the impact of the more common experience of dysphoria. It is therefore unclear whether a mild mood disturbance such as dysphoria significantly influences interpersonal interactions, and if it does, what the nature of that impact is. One hypothesis is that dysphoric and nondysphoric subjects are both relatively nondepressed, so they would both prefer nondepressed partners; in that case, both groups should be more satisfied with nondysphoric partners. An alternate hypothesis, suggested by the research on similarity, is that both dysphoric and nondysphoric people find an interaction more satisfying if the partner exhibits a similar mood. The first goal of this study, then, was to compare the satisfaction of dysphoric and nondysphoric individuals as they interacted with partners of similar or dissimilar moods.

The second goal was to examine the mechanisms by which the level of dysphoria might influence a subject's satisfaction with the interaction. A number of investigators have reported that depressed people generate more negative statements, even with strangers (Blumberg \& Hokanson, 1983; Gotlib \& Robinson, 1982; Jacobson \& Anderson, 1982). According to one interpretation, these negative statements can lead to rejection by a partner (Gurtman, 1987). For this reason, the present study compared the number of negative topics that dysphoric and nondysphoric subjects introduced into the conversation. In addition, the literature on depression has suggested that depressed people are more likely than nondepressed people to make unsolicited self-disclosures during an initial encounter (Jacobson \& Anderson, 1982), and this tendency may cause depressed people to seem less well adjusted and less likable (Chaiken \& Derlega, 1974a, 1974b). Therefore, the present study also compared the number of intimate topics that dysphoric and nondysphoric subjects introduced into the conversation. Finally, in order to examine the nature of the subjects' actual interpersonal style, their behaviors were rated along the dimensions of warmth and assertiveness by their partners and by objective observers.

\section{Method}

\section{Subjects}

Eighty Stanford undergraduates participated in partial fulfillment of an introductory psychology course requirement. Subjects were randomly placed into 40 same-sex pairs ( 20 male and 20 female). One pair of males was eliminated because they previously knew each other, and one pair of females was eliminated because of incomplete responses to one of the inventories, leaving a total of 38 pairs. In order to obtain a stable and reliable assessment of whether or not a subject was dysphoric, each subject completed two measures of depression. The first measure was the Center for Epidemiological Studies Depression Inventory (CES-D; Radloff, 1977), a 20-item self-report instrument in which respondents describe the frequency of depressive experiences during the past week on a 4-point scale. This measure was administered at the beginning of the experimental session. The other measure was the short form of the Beck Depression Inventory (BDI; Beck \& Beck, 1972), a 13-item measure with known reliability and validity; it was administered before the subject left the experimental session.

The Pearson $r$ between the CES-D and BDI scores for all subjects was .75 , showing consistency between the two measures. Therefore, as a way of increasing the stability of the measure of depression (Einhorn, Hogarth, \& Klempner, 1977; Horowitz, Inouye, \& Siegelman, 1979), the two measures were each converted to $z$ scores and summed. Cronbach's alpha for this aggregated measure was.85. Subjects with positive $z$ scores on this combined measure were considered dysphoric. Using this criterion, there were 31 dysphoric subjects and 45 nondysphoric subjects. The mean score on the CES-D was $19.23(S D=6.97)$ for the dysphoric subjects and $8.33(S D=3.70)$ for the nondysphoric subjects; the corresponding means on the short form of the BDI were 4.26 ( $S D=$ $2.32)$ and $0.78(S D=.97)$. (Scores above 16 on the CES-D and scores above 4 on the short form of the BDI are generally considered indicative of depression; Beck \& Beck, 1972; Roberts \& Vernon, 1983). Categorized in this way, the subjects formed three types of dyads: homogeneous nondysphoric dyads, homogeneous dysphoric dyads, and mixed dyads. Fourteen subjects were in the homogeneous dysphoric dyads, 28 were in the homogeneous nondysphoric dyads, and the rema'ning 34 were in the mixed dyads.

The mean depression scores were comparable for nondysphoric subjects in the homogeneous and mixed groups; the mean $z$ scores, respectively, were -0.61 and $-0.57, t(43)=0.36, p>.25$. Similarly, the mean depression scores were comparable for dysphoric subjects in the homogeneous and mixed groups; those mean $z$ scores, respectively, were 0.93 and $0.81, t(29)=0.41, p>.25$. Furthermore, the subjects' depression scores were stable. For subjects in each of the three groups, the scores initially obtained on the CES-D (expressed as $z$ scores) were compared with those obtained at the end of the session on the BDI (also expressed as $z$ scores). No group showed a significant change (all $t s<1.2, p s>.20$ ), nor did the three groups differ significantly from each other in the magnitude of their change, $F(2,73)=1.54, p>.20$.

\section{Topics}

During the procedure, subjects were presented with a list of 90 selfrelevant topics of conversation. This list contained 15 topics from each of the following 6 categories: positive/low-intimacy, positive/mediumintimacy, positive/high-intimacy, negative/low-intimacy, negative/ medium-intimacy, and negative/high-intimacy. These topics were selected, with some slight modifications of wording, from a list of 671 topics prepared by Taylor and Altman (1966). Approximately half of the topics were eliminated because they were not suitable for an undergraduate subject population. Students in the introductory psychology class at Stanford University rated the valence (negative, neutral, or posi- 
tive) of the remaining topics. Each student rated approximately 100 topics. The instructions read:

For each of the topics listed below, please imagine yourself talking about this topic to another student of the same sex. Then consider whether the content of your conversation is likely to be positive or negative. Please circle " + " if it seems positive and "-" if it seems negative. Circle " 0 " if it seems neutral.

Approximately 25 students rated each topic.

The valence of each topic was defined as the difference in the number of positive and negative judgments divided by the total number of judgments. This measure could range from +1 to -1 . To avoid topics that were neutral or ambiguous in content, we eliminated topics whose overall valence was between +.15 and -.15 and those that were rated neutral more than $50 \%$ of the time. A rating of each topic's intimacy was available from the norms provided by Taylor and Altman (1966). The three levels of intimacy were defined as follows: low intimacy (2.00-4.99), medium intimacy (5.00-6.99), and high intimacy (above 7.00). The three levels of intimacy were combined with the two levels of valence (positive or negative) to produce six categories of items, and 15 items were selected from each category as being topics appropriate for an undergraduate student population. In addition, to ensure that the full range of valence was represented in each category, we divided the valence continuum into three equally numerous segments (e.g., .15 to $.40, .40$ to .70 , and .70 to 1.00 ) and selected five topics from each segment to form the 15 topics of a category. Some examples of the topics are "Things I like about my mother" (intimate and positive), "What I am most afraid of" (intimate and negative), and "Situations which make me impatient" (nonintimate and negative). The 90 topics in the resulting list were then used as possible topics of conversation during the experimental procedure.

\section{Procedure}

After preliminaries, the subjects rated themselves on the CES-D and on an interpersonal adjective checklist. The experimenter then explained that the study concerned communication patterns. The partners were instructed to talk to each other for about half an hour. They were told to talk in turns; that is, first one partner should speak, then the other, then the first, and so on. They were also told that there was a time limit on each turn; they were to talk for only a minute and a half at a time. On each turn, they were to select a topic from the list of 90 topics and talk on that topic in any way they wished. They could choose any topic from the list, but once a topic had been used, it was not to be chosen again. A panel of five buttons also appeared in front of each subject (but shielded from the partner). The buttons were labeled not satisfied, somewhat satisifed, moderately satisfied, quite satisfied, and very satisfied. After every turn the partners-both speaker and listener-used the buttons to rate how satisfied they were with how the conversation was going.

Several practice trials occurred to familiarize the subjects with the procedure. The first speaker was selected by flipping a coin. Then the experimenter went into an adjoining room and inconspicuously observed the subjects through a one-way mirror. The experimenter timed the subjects and, if they did not stop after a minute and a half, intervened over an intercom. After each subject had spoken 10 times, the experimenter stopped the conversation.

Then the subjects completed two additional forms. First, they completed a checklist version of the Interpersonal Adjective Scales (IAS; Wiggins, 1979), marking those adjectives that accurately described their partner. The IAS consists of 128 interpersonal adjectives organized into eight scales representing different octants of a twodimensional space defined by the dimensions of warmth and assertiveness. Thus, this measure provided an assessment of subjects' percep- tions of their partners' warmth and assertiveness. Second, the subjects completed the BDI as a way of reassessing their level of dysphoria. Finally, upon completion of the experiment, the subjects were debriefed.

All interactions were recorded on videotape. In order to minimize the intrusiveness of the camera, it was placed behind a very narrow, inconspicuous one-way mirror; no subject commented on its presence. Three undergraduate observers, who were aware neither of the hypotheses of the study nor the partners' moods, individually rated each speaker (on Trials 1, 2, 3, and 6) on a shortened version of the IAS, which contained four interpersonal adjectives per octant that were judged (by the two authors and three graduate students) to have the highest frequency of usage for describing two interactants. In addition, the observers separately rated the listener's degree of receptiveness on a 7-point scale. It should be noted that because the observers could see both partners while making their ratings, it was possible for their ratings of one partner to be influenced by the concurrent behavior of the other partner.

\section{Data Analysis}

When two partners interact with each other, as they did in this study, they may mutually affect each other's scores in a way that induces a statistical dependency in the data. That is, the partners' scores within a given condition may be correlated with each other, and the magnitude of the correlation may vary from one condition to the next. Variances may also differ from one condition to the next. Therefore, in analyzing the data of this study, we needed a statistical procedure that would circumvent these statistical difficulties and allow us to examine three sources of variance-the subject's level of dysphoria, the partner's level of dysphoria, and the interaction between the two variables; we expected the interaction to be the significant source of variance. Kraemer and Jacklin (1979) have developed a statistical procedure for analyzing data of this type. Their procedure is based on an analysis of variance model and first derives four sets of scores from the raw datathe mean score of each dyad in each of the three groups and the difference score of each dyad in the mixed group. Then, from the mean and variance of each set, the procedure estimates the size of each of the three effects and their standard errors. This procedure has also been discussed by Kenny (1988), and we used it in the analyses described below.

\section{Results}

\section{Satisfaction Judgments}

We considered whether subjects in the different conditions differed in how much satisfaction they reported. Each response describing the subjects' satisfaction was converted to a numerical scale from 1 to 5 . Table 1 shows the mean satisfaction across the 10 trials for subjects in each condition. First we determined whether the ratings by partners within a dyad were significantly correlated with one another. The intraclass $r$ was .45 , corresponding to an $F(37,38)=2.65, p<.01$. Because the responses within dyads were not statistically independent, the procedure recommended by Kraemer and Jacklin (1979) was used to examine the effects of the subject's mood, the partner's mood, and the interaction between the two. These three effects were, respectively, $.00(p>.20), .02(p>.20)$, and $.18(z=2.3, p<$ .025 ). Thus, neither the mood of the subject nor that of the partner individually affected the subjects' satisfaction ratings, but the interaction between them did produce a significant effect. 
Table 1

Mean Satisfaction Ratings Across 10 Trials as a Function of Mood Similarity, Speaker Mood, and Respondent's Role

\begin{tabular}{ccc}
\hline & \multicolumn{2}{c}{ Respondent's role } \\
\cline { 3 - 3 } $\begin{array}{c}\text { Mood similarity and } \\
\text { speaker mood }\end{array}$ & Speaker & Listener \\
\hline Homogeneous & & \\
Nondysphoric & 3.82 & 4.10 \\
Dysphoric & 3.76 & 4.16 \\
Mixed & & \\
Nondysphoric & 3.52 & 3.75 \\
Dysphoric & 3.40 & 3.70 \\
\hline
\end{tabular}

In order to examine the interaction further, the mean satisfaction rating of each dyad was classified as being above or below the grand mean (3.78). The proportion of dyads showing a mean satisfaction rating above the grand mean was .71 for the homogeneous dysphoric group, .86 for the homogeneous nondysphoric group, and .29 for the mixed group. To test this relationship, a $2 \times 2$ contingency table was prepared relating the mean satisfaction rating (high or low) to the homogeneity or heterogeneity of the dyads. The resulting chi-square $(d f=1)$ was $10.1, p<.005$. Thus, subjects in the homogeneous dyads reported greater satisfaction than subjects in the mixed dyads.

Figure 1 shows the mean satisfaction rating for each group of subjects across the 10 trials. The figure suggests that the effect of the interaction between the partners' moods became increasingly pronounced across trials. In order to evaluate this change, the procedure of Kraemer and Jacklin (1979) was applied separately to the data of the first five trials and to the data of the last five trials. The effect of the interaction was not significant on the first five trials (effect size $=0.12, z=1.4, p>.10$ ), but it was highly significant on the last five trials (effect size $=0.25, z=$ $3.3, p<.001$ ). To test the interaction directly, we computed for each subject the difference between the mean satisfaction on the first five trials and the mean satisfaction on the last five trials. The procedure of Kraemer and Jacklin (1979) was applied to these difference scores. The main effects of the subject's mood and the partner's mood were not significant (both effect sizes $=.03, z \mathrm{~s}<.7, p \mathrm{~s}>.2$ ), but the effect of the interaction was highly significant (effect size $=.12, z=3.4, p<.0001$ ). Thus, the difference in satisfaction between the homogeneous and the mixed dyads tended to increase during the interaction.

Figure 2 shows the mean satisfaction rating across trials for speakers and listeners separately. The figure suggests that subjects initially preferred the listener role to the speaker role but that this difference decreased over time. In order to examine the effect of the subjects' conversational role as speaker or listener on the subjects' satisfaction across trials, a mixed design analysis of variance (ANOVA) was performed on the satisfaction ratings, with the dyad as the unit of analysis. This analysis contained type of dyad (homogeneous vs. mixed) as a betweendyads variable, and conversational role (speaker vs. listener) and trials as within-dyads variables. The results showed a signifcant effect of conversational role, $F(1,36)=28.76, p<.001$, as well as a significant interaction with trials, $F(9,324)=2.81, p<$ .005 . Listeners were generally more satisfied than speakers, but this difference was most pronounced on the early trials. In addition, the results of this analysis confirmed the effect of dyad type, $F(1,36)=6.89, p=.01$, again showing that the homogeneous dyads were more satisfied than the mixed dyads. Also, type of dyad interacted with trials, $F(9,324)=2.11, p<$ .05 , again showing that the difference between homogeneous and mixed dyads increased across trials.

\section{Ratings of Partners}

After the interaction, the subjects rated their partners on the IAS. Following Wiggins, Phillips, and Trapnell (1989), the subjects' ratings were aggregated to yield an overall rating of their partners along a dimension of warmth (from cold to warm) and along a dimension of assertiveness (from passive to assertive). In order to determine whether the partners' ratings of each other were significantly correlated, an intraclass correlation was computed for each dimension. The intraclass $r s$ were -.026 for ratings of warmth and 208 for ratings of assertiveness. Neither intraclass $r$ was significant; in both cases, $F(37,38)\langle 1.53, p\rangle$ .05 . Because the ratings within dyads seemed to be statistically independent, individual subjects were used as the unit of analysis in the following analyses, as recommended by Kenny (1988). Two-way ANOVAS were performed separately on the ratings of warmth and assertiveness, with mood of rater and mood similarity as independent variables. The results of these analyses showed that the subjects in the homogeneous dyads rated their partners as warmer than subjects in the mixed dyads, $F(1,72)=$ $4.95, p<.05$. Thus, subjects in the homogeneous dyads not only expressed greater satisfaction during the interaction, but they also rated their partners as warmer after the interaction. This effect was further confirmed using the procedure of Kraemer and Jacklin (1979); the results of that analysis again showed a significant interaction between mood of subject and mood of partner (effect size $=0.62, z=1.98, p<.05$ ). Because the two simple effects were not significant, the observed differences could not be ascribed either to the subject's mood or to the partner's mood alone. Finally, a $2 \times 2$ contingency table was prepared relating the mean warmth rating for each dyad (above or below the overall mean) to the homogeneity or heterogeneity of the dyads. The resulting chi-square $(d f=1)$ was $6.30, p<.025$.

\section{Topic Choices}

Each of the 90 topics was selected at least once. In general, positive topics were selected significantly more often than negative topics, $\chi^{2}(1)=51.58, p<.001$. Positive topics constituted $63.0 \%$ of the selections. High-intimacy topics were selected significantly less often than medium- or low-intimacy topics, $\chi^{2}(2)=44.60, p<.001$. High-intimacy topics constituted $22.4 \%$ of the selections; medium-intimacy topics, $36.0 \%$; and low-intimacy topics, $41.6 \%$. The two effects were independent of each other, $\chi^{2}(2)=1.81, p>.30$.

Next, we examined both for intimacy and for valence whether the two partners' topic choices were independent of each other. (Topic valence was defined as the difference in the number of positive and negative judgments divided by the total number of judgments.) The intraclass $r s$ for both variables were .00 . Because the partners' topic choices were uncorrelated with 


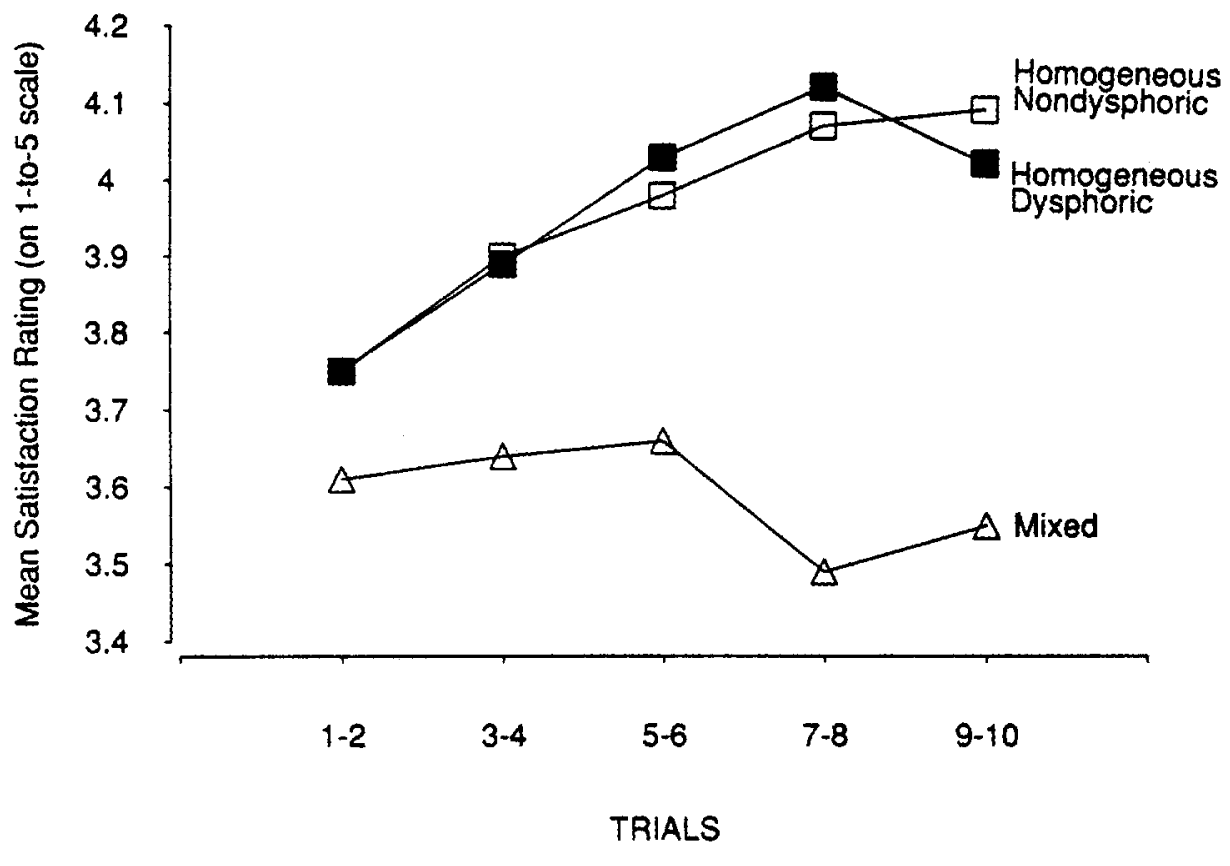

Figure 1. Mean satisfaction ratings on a scale from 1 (not at all satisfied) to 5 (very satisfied) on successive pairs of trials for homogeneous nondysphoric, homogeneous dysphoric, and mixed dyads.

respect to both valence and intimacy, the individual subjects were used as the unit of analysis in the following analyses (Kenny, 1988). Two-way ANOVAs were performed separately on valence and intimacy, with mood of rater and mood similarity as independent variables. These analyses revealed that signifcant effects only occurred with respect to valence. Specifically, there was a significant effect of trials, $F(9,648)=1.94, p<.05$, and a significant interaction between mood similarity and trials, $F(9,648)=2.09, p<.05$. In general, the mean valence of the topics selected was constant across trials for the homogeneous dyads but decreased over trials for the mixed dyads. The data showed a significant linear decrease in topic valence over trials for mixed dyads, $F(1,297)=10.16, p<.01$, but not for homogeneous dyads, $F(1,369)=0.85, p>.25$. (This analysis was also performed separately on the homogeneous dysphoric and homogeneous nondysphoric dyads; in both cases, $F<1$, $p>.25$ ). Furthermore, within the mixed dyads, the trend was more pronounced for the dysphoric subjects, $F(1,144)=7.31$, $p<.01$, than for the nondysphoric subjects, $F(1,144)=3.39$, $p<.1$. Thus, as the conversation proceeded, subjects in mixed dyads not only expressed greater dissatisfaction, but also tended to talk about more negative topics. To illustrate this point, the topics "Long-range worries or concerns that I have about my health" and "How often I have spells of the blues and what they are about" were never selected by subjects in the mixed dyads during the first five trials, but they were selected seven times by those subjects during the last five trials.

Dysphoric subjects who talked with nondysphoric partners tended to select more negative topics than dysphoric subjects who talked with dysphoric partners; the mean topic valences for each group were, respectively, 08 and $.22, t(29)=2.17, p<$ .05 . For the two nondysphoric groups, the means were .17 and
17. Thus, dysphoric subjects tended to select topics of lower valence only when they were interacting with nondysphoric partners. This result is consistent with the results of previous studies that examined the statements of dysphoric subjects talking to nondysphoric partners.

In addition, correlations were computed between each of these topic characteristics and the subjects' satisfaction (a) when the respondent was the listener and (b) when the respondent was the speaker. Significant relationships only occurred when the respondent was the listener. First, the relationship between the intimacy of the topics and the listeners' satisfaction was significant in the homogeneous dyads: for the nondysphoric dyads, $r(26)=.58, p=.001$; for the dysphoric dyads, $r(12)=.45$, $p=.05$. Thus, for these satisfied dyads, satisfaction was greater for more intimate topics. For the mixed dyads, the correlation was not significant, $r(32)<.10, p\rangle .20$. In addition, topic valence was negatively correlated with the satisfaction of dysphoric listeners in the mixed dyads, $r(32)=-.56, p=.01$. That is, dysphoric subjects listening to nondysphoric partners were more satisfied with negative topics (perhaps in hopes that their partners were more like themselves). Finally, for each dyad, the partners' ratings on the warmth dimension of the IAS were related to the mean intimacy and the mean valence of the topics they selected; the Pearson $r$ across all dyads for intimacy and valence, respectively, were $r(36)=.43, p<.01$, and $r(36)=$ $.28, p<.05$. Thus, subjects rated partners who had chosen more intimate or more positive topics as warmer.

\section{Ratings by Objective Observers}

In order to determine whether the difference between homogeneous and mixed dyads can be judged objectively, observers 


\section{Speakers' Satisfaction}
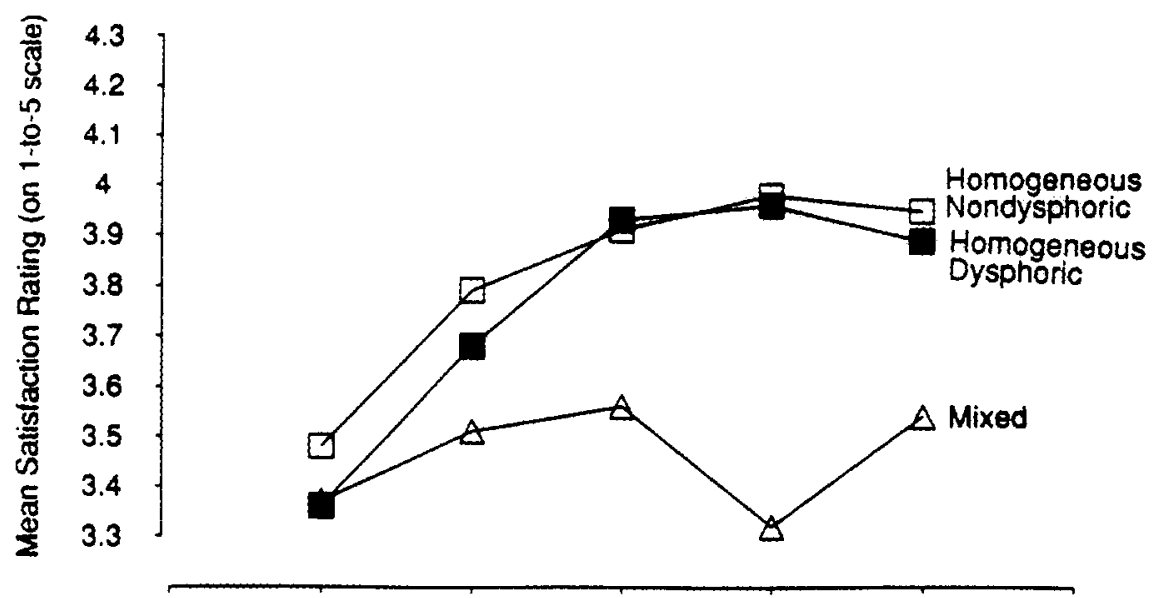

$1-2 \quad 3-4 \quad 5-6 \quad 7-8 \quad 9-10$

TRIALS

Listeners' Satisfaction

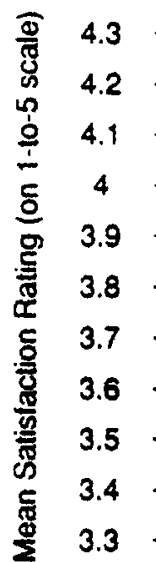
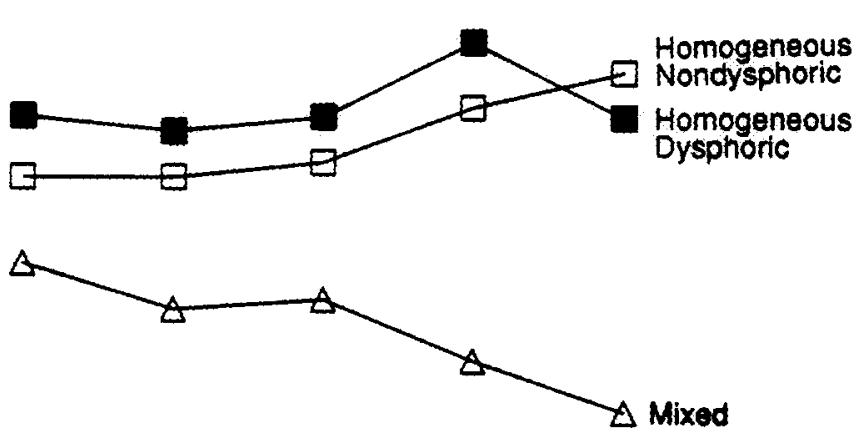

$\begin{array}{lllll}1.2 & 3.4 & 5.6 & 7.8 & 9-10\end{array}$

TRIALS

Figure 2. Mean satisfaction ratings on a scale from 1 (not at all satisfied) to 5 (very satisfed) on successive pairs of trials for speakers and listeners in homogeneous nondysphoric, homogeneous dysphoric, and mixed dyads.

who were unaware of subjects' depression scores were asked to watch videotapes of four trials of the interaction (Trials 1, 2, 3, and 6) and rate the behavior of each speaker on the IAS. These ratings, averaged across observers, provided a measure of the speakers' interpersonal style on each dimension of the IAS (warmth and assertiveness). The intraclass $r$ for judgments of 
assertiveness was $.19, F(37,38)=1.46, p>.10$, indicating that the judgments of the two partners were not related. Therefore, the judgments of assertiveness for each subject were treated as independent and subjected to a mixed ANOVA with subject's mood and mood similarity as between-subjects variables and with trials (early vs. late) as a within-subjects variable. The only significant effect was an increase in assertiveness from the early to the late trials, $F(1,72)=16.11, p<.001$.

For judgments of warmth, the intraclass $r$ was $.44, F(37,38)=$ $2.61, p<.01$, indicating that observers who rated one member of a dyad high in warmth tended to do the same for the other member of the dyad. Therefore, we first examined the data using the procedure recommended by Kraemer and Jacklin (1979). None of the effects were significant (all $z \mathrm{~s}<1.5, p \mathrm{~s}>$ $.10)$, indicating that the observers' ratings did not discriminate among the different conditions. Next, to examine changes over trials, we performed an ANOVA on these judgments with homogeneous versus mixed dyads as a between-dyads variable and trials (early vs. late) as a within-dyads variable. There was a significant increase in warmth over trials, $F(1,36)=6.31, p<$ .05 . Thus, across all dyads, subjects tended to be judged both warmer and more assertive as the interaction progressed.

However, other evidence from the IAS suggested that observers did differentiate between satisfied and unsatisfied dyads in their ratings of the subjects' display of arrogance (hostile assertiveness). The intraclass $r$ on this subscale was not significant, $r=-.15, F(37,38)=.74, p>.10$, so judgments of the two partners were treated as independent and subjected to a mixed ANOVA. The results of this analysis showed a significant interaction between the speaker's mood and mood similarity, $F(1,72)=4.67, p<.05$, with the nondysphoric subjects in the mixed dyads being judged to exhibit significantly more arrogance than their partners. In addition, the results showed a significant decrease in arrogance across all groups over trials, $F(1,72)=4.60, p<.05$.

Finally, we correlated the observers' ratings of warmth, assertiveness, and receptiveness with other characteristics of the interaction. The intraclass $r$ for receptiveness was $.62, F(37,38)=$ $4.25, p<.01$. Because a given measure was not always independent across the two members of a dyad, corresponding measures were averaged across the two partners to yield a single dyad score, and these dyad scores were then correlated with each other. First, we correlated the ratings on each interpersonal dimension with the intimacy and valence of the topics the partners had selected. Dyads who spoke about more intimate topics were rated as being warmer, $r(36)=.35, p<.05$, more receptive, $r(36)=.38, p=.01$, and more assertive, $r(36)=$ $.30, p<.05$. Dyads who spoke about more positive topics were also rated as being more receptive, $r(36)=.35, p<.05$. Second, we correlated the ratings on each interpersonal dimension with the partners' ratings of each other. Partners who rated each other as warmer were judged as warmer, $r(36)=.43, p<.01$, and more receptive, $r(36)=.56, p<.01$. Finally, we correlated the observers' ratings with dyad satisfaction. More satisfied dyads were rated as more receptive, $r(36)=.32, p<.05$, and more assertive, $r(36)=.42, p=.005$.

\section{Discussion}

The purpose of this study was to compare dysphoric and nondysphoric people as they interacted with people of similar or dissimilar mood. The results showed that people in homogeneous dyads (in which both partners were dysphoric or both partners were nondysphoric) were more satisfied, and their satisfaction increased as the conversation proceeded. People in mixed dyads were less satisfied, perceived each other as colder, and spoke about increasingly negative topics. Thus, in accord with other research showing that similarity leads to liking, the crucial determinant of interactional satisfaction was neither the mood of the subject nor the mood of the partner, but their similarity in mood. We therefore need to consider the mechanisms by which similarities and differences between partners influence their satisfaction with each other.

One possible mechanism is contained in the interpersonal theory of personality (Horowitz \& Vitkus, 1986; Kiesler, 1983; Leary, 1957; Orford, 1986; Wiggins, 1982). This theory contains two basic postulates about interpersonal interactions. First, it claims that interpersonal behavior can be organized along two dimensions-a dimension of affiliation that ranges from hostile to friendly behavior and a dimension of power that ranges from submissive to dominating behavior. Second, it claims that two interacting people reciprocally influence each other as they interact (Carson, 1969; Darley \& Fazio, 1980; Kiesler, 1983; Leary, 1957; Sullivan, 1953). Interpersonal behaviors expressed by one partner are assumed to invite reactions from the other partner that are complementary (similar with respect to affiliation and reciprocal with respect to power).

This theory has been used to describe interactions with depressed people (Horowitz \& Vitkus, 1986). Because depressed people experience a lack of efficacy, expect future failure, and think self-derogating thoughts, their behavior conveys a submissive interpersonal stance that invites other people to adopt a dominating role (e.g, advice giving), which in turn invites the depressed person to remain submissive, thereby sustaining the depression (Altman \& Wittenborn, 1980; Beck, 1967; Blumberg \& Hokanson, 1983; Cofer \& Wittenborn, 1980; Coyne, 1976b; Gotlib \& Robinson, 1982; Hokanson, Sacco, Blumberg, \& Landrum, 1980). As a result, the depressed person continues to feel depressed and the partner eventually comes to feel frustrated (Horowitz \& Vitkus, 1986).

However, when two depressed people interact with each other, it is possible that neither dominates the other, thereby avoiding this vicious cycle. In the present study, whereas dysphoric people in homogeneous dyads did not exhibit any distinctive behavior or characteristic by which observers could judge them to be dysphoric, dysphoric people in mixed dyads did show evidence of their dysphoria. For example, the observers' ratings did not differentiate between dysphoric subjects and nondysphoric subjects in homogeneous dyads, but they did rate the nondysphoric partners of mixed dyads as more arrogant (high in hostile dominance) than the dysphoric partners. Moreover, dysphoric subjects in mixed dyads (but not in homogeneous dyads) were more likely to select negative topics (topics that tended to be self-derogatory). Thus, the vicious cycle described by the interpersonal model appears to have been more likely to arise in the mixed dyads, thereby explaining both partners' relative dissatisfaction.

A second explanation of the relationship between similarity and interpersonal satisfaction is provided by social comparison theory. Social comparison refers to the fact that people are mo- 
tivated to compare their reactions to the reactions of others (Festinger, 1954). When two similar people interact with each other, they like each other because the reactions of one validate the corresponding reactions of the other; conversely, when two dissimilar people interact, they dislike each other because the reactions of one invalidate the corresponding reactions of the other (Byrne, 1971; Schachter, 1959). Thus, according to this theory, to the extent that partners in homogeneous dyads validate each other's reactions, they feel more satisfied with their interaction. Moreover, the need for confirmation may be greater when partners are talking about more intimate topics. That would explain why in homogeneous dyads the subjects' satisfaction was greater when they were listening to a partner who talked about more intimate topics.

A third theory to explain why similarity leads to greater satisfaction is that people's satisfaction with an interaction depends on whether or not they believe their partners like them. According to this theory, subjects believe that similar partners like them better, leading them to experience greater satisfaction (Condon \& Crano, 1988). (In the present study, subjects in the homogeneous dyads did, in fact, rate their partners as warmer.) Conversely, subjects with dissimilar partners believe that their partners dislike them, and that inference may lower their satisfaction with the interaction.

These theories are not mutually exclusive, and all may have contributed to the greater satisfaction of subjects in the homogeneous dyads. The relative importance of the different mechanisms will depend on the person and the situation. For example, the research on distress and affiliation would suggest that dysphoric people may be more concerned with consensual validation than nondysphoric people. The importance of a particular mechanism may also depend on the way dysphoria is defined. Social comparison may be more relevant to studies that examine self-reported attitudes toward the self, whereas interpersonal theory may be more relevant to studies that examine behavioral manifestations of dysphoria. Finally, the situational context may also influence which mechanisms are most important. For example, some studies have examined naturalistic interactions, whereas others have examined reactions to targets in the absence of any interaction. The present study examined constrained interactions in which subjects had to take turns and each turn was time limited. Because the interpersonal theory focuses on interactional dynamics, it may be more germane to unconstrained, face-to-face interactions than to the present context. Inferred liking, on the other hand, may be more germane to constrained interactions, and social comparison theory may be most germane when there is no interaction at all.

A few studies have found that similarity can lead to avoidance or disliking when the similar other has undesirable characteristics. In one study (Novak \& Lerner, 1968), subjects were led to believe (a) that their attitudes were either similar or dissimilar to those of another subject and (b) that the other subject either did or did not have a history of mental disturbance. Subjects were more willing to interact with a similar (versus dissimilar) normal partner, but were less willing to interact with a similar (versus dissimilar) disturbed partner. In another study (Taylor \& Mettee, 1971), subjects believed their scores on a personality test were either similar or dissimilar to those of a con- federate who was acting either pleasant or obnoxious. Subjects liked the pleasant similar confederate more than the pleasant dissimilar confederate, but disliked the obnoxious similar confederate more than the obnoxious dissimilar confederate. These studies differ from ours in several ways. First, these studies deliberately led subjects to focus on whether or not they were similar to their partner, whereas in our study we deliberately did not let subjects know whether or not they were similar. Second, mental illness and obnoxious behavior are clearly socially undesirable characteristics, whereas the dysphoric individuals in our study generally did not show clearly undesirable characteristics. Finally, whereas in our study the similarity was real, in these studies the similarity was artificial; indeed, most subjects were probably not similar to the undesirable other. Thus, similarity may only lead to avoidance or disliking in contexts in which the similarity is salient and the similar other displays socially undesirable characteristics that are not felt to be characteristic of the self.

The present study examined the interactions of college students who were experiencing the normal dysphoria of everyday life, not those of individuals who were experiencing the more severe form of depression that requires clinical intervention. It is conceivable that the present results would not hold for individuals as severely depressed as those studied by Coyne (1976a). In order to determine whether the results of this study would generalize to a population of clinically depressed individuals, a separate study would be needed comparing clinically depressed subjects in mixed or homogeneous dyads. Also, the present results described subjects' reactions to an initial encounter, and the conclusions may have to be modified in describing more enduring relationships. Nonetheless, many interactions of everyday life do involve casual encounters between individuals who may be experiencing dysphoria, and the present findings 'underscore the importance of these individuals' similarity in mood in determining the fate of their subsequent interaction.

\section{References}

Altman, J. H., \& Wittenborn, J. R. (1980). Depression-prone personality in women. Journal of Abnormal Psychology, 89, 303-308.

Amstutz, D. K., \& Kaplan, M. F. (1987). Depression, physical attractiveness, and interpersonal acceptance. Journal of Social and Clinical Psychology, 5, 365-377.

Beck, A. T. (1967). Depression: Clinical, experimental, and theoretical aspects. New York: Hoeber.

Beck, A. T., \& Beck, R. W. (1972). Screening depressed patients in family practice: A rapid technique. Postgraduate Medicine, 52, $81-85$.

Bell, P. A. (1978). Affective state, attraction, and affiliation: Misery loves happy company, too. Personality and Social Psychology Bulletin, 4, 616-619.

Blumberg, S. R., \& Hokanson, J. E. (1983). The effects of another person's response style on interpersonal behavior in depression. Journal of Abnormal Psychology, 92, 196-209.

Boswell, P. C., \& Murray, E. J. (1981). Depression, schizophrenia, and social interaction. Journal of Consulting and Clinical Psychology, 49, 641-647.

Byrne, D. (1971). The attraction paradigm. New York: Academic Press. Carson, R. C. (1969). Interaction concepts of personality. Chicago: Aldine. 
Chaiken, A. L., \& Derlega, V. J. (1974a). Liking for the norm-breaker in self-disclosure. Journal of Consulting and Clinical Psychology, 42, 117-129.

Chaiken, A. L, \& Derlega, V. J. (1974b). Variables affecting the appropriateness of self-disclosure. Journal of Consulting and Clinical Psychology, 42, 588-593.

Coates, D., \& Winston, T. (1983). Counteracting the deviance of depression: Peer support groups for victims. Journal of Social Issues, 39. 169-194.

Cofer, D. H, \& Wittenborn, J. R. (1980). Personality characteristics of formerly depressed women. Journal of Abnormal Psychology, 89, 309-314.

Condon, J. W., \& Crano, W. D. (1988). Inferred evaluation and the relation between attitude similarity and interpersonal attraction. Journal of Personality and Social Psychology, 54, 789-797.

Coyne, J. (1976a). Depression and the response of others. Journal of Abnormal Psychology, 85, 186-193.

Coyne, J. (1976b). Toward an interactional description of depression. Psychiatry, 39, 28-39.

Darley, J. M., \& Fazio, R. H. (1980). Expectancy confirmation processes arising in the social interaction sequence. American Psychologist, 35, 867-881.

Duck, S. W. (1973). Personality similarity and friendship choice: Similarity of what, when? Journal of Personality, 41, 543-558.

Einhorn, H. J., Hogarth, R. M., \& Klempner, E. (1977). Quality of group judgment. Psychological Bulletin, 84, 158-172.

Festinger, L. (1954). A theory of social comparison processes. Human Relations, 7, 117-140.

Gibbons, F X. (1986). Social comparison and depression: Company's effect on misery. Joumal of Personality and Social Psychology, 51. $140-148$.

Gotlib, 1., \& Beatty, M. (1985). Negative responses to depression: The role of attributional style. Cognitive Therapy and Research, 9 , 91-103.

Gotlib, I. H., \& Robinson, L. A. (1982). Responses to depressed individuals: Discrepancies between self-report and observer-rated behav. ior. Journal of Abnormal Psychology, 91, 231-240.

Gough, H. G. (1964). California Psychological Inventory: Manual (2nd ed.). Palo Alto, CA: Consulting Psychologists Press.

Gurtman, M. B. (1987). Depressive affect and disclosures as factors in interpersonal rejection. Cognitive Therapy and Research, 11, 87-100.

Hammen, C, \& Peters, S. (1977). Differential responses to male and female depressive relations. Journal of Consulting and Clinical Psychology, 45, 994-1001.

Hammen, C., \& Peters, S. D. (1978). Interpersonal consequences of depression: Responses to men and women enacting a depressed role. Journal of Abnormal Psychology, 87, 322-332.

Hokanson, J. E, Sacco, W. P., Blumberg, S. R., \& Landrum, G. C. (1980). Interpersonal behavior of depressive individuals in a mixed-motive game. Journal of Abnormal Psychology, 89, 320-332.

Horowitz, L. M., Inouye, D., \& Siegelman, E. Y. (1979). On averaging judges' ratings to increase their correlation with an external criterion. Journal of Consulting and Clinical Psychology, 47, 453-457.

Horowitz, L. M, \& Vitkus, J. (1986). The interpersonal basis of psychiatric symptoms. Clinical Psychology Review, 6, 443-469.

Howes, M. J., \& Hokanson, J. E. (1979). Conversational and social responses to depressive interpersonal behavior. Journal of Abnormal Psychology, 88, 625-634.

Jacobson, N. S., \& Anderson, E. A. (1982). Interpersonal skill and depression in college students: An analysis of timing of selfdisclosures. Behavior Therapy, 13, 271-282.

Kenny, D. A. (1988). The analysis of data from two-person relationships. In S. Duck, S. Hobfoll, W. Ickes, \& B. Montgomery (Eds.), The handbook of personal relationships: Theory, research, and interventions (pp. 57-77). Chichester: Wiley.

Kiesler, D. J. (1983). The 1982 interpersonal circle: A taxonomy for complementarity in human transactions. Psychological Review, 90, 185-214.

Kraemer, H. C., \& Jacklin, C. N. (1979). Statistical analysis of dyadic social behavior. Psychological Bulletin, 86, 217-224.

Leary, T. F (1957). Interpersonal diagnosis of personality. New York: Ronald Press.

Marks, T, \& Hammen, C. L. (1982). Interpersonal mood induction: Situational and individual determinants. Motivation and Emotion, 6 , 387-399.

Newcomb, T. M. (1961). The acquaintance process. New York: Holt, Rinehart, and Winston.

Novak, D. W., \& Lerner, M. J. (1968). Rejection as a function of perceived similarity. Journal of Personality and Social Psychology, 9, 147-152.

Orford, J. (1986). The rules of interpersonal complementarity: Does hostility beget hostility and dominance, submission? Psychological Review, 93, 365-377.

Radloff, L. S. (1977). The CES-D scale: A self-report depression scale for research in the general population. Journal of Applied Psychological Measurement, I, 385-401.

Roberts, R. E., \& Vernon, S. W. (1983). The Center for Epidemiologic Studies Depression Scale: Its use in a community sample. American Journal of Psychiatry, 140, 41-46.

Rosenblatt, A., \& Greenberg, J. (1988). Depression and interpersonal attraction: The role of perceived similarity. Journal of Personality and Social Psychology, 55, 112-119.

Schachter, S. (1959). The psychology of affiliation. Stanford, CA: Stanford University Press.

Stephens, R. S., Hokanson, J. E., \& Welker, R. (1987). Responses to depressed interpersonal behavior: Mixed reaction in a helping role. Journal of Personality and Social Psychology, 52, 1274-1282.

Strack, S., \& Coyne, J. C. (1983). Social confirmation of dysphoria: Shared and private reactions to depression. Journal of Personality and Social Psychology, 44, 798-806.

Sullivan, H. S. (1953). The interpersonal theory of psychiatry. New York: Norton.

Taylor, D. A., \& Altman, I. (1966). Intimacy scaled stimuli for use in studies of interpersonal relationships (Research Report No. 9). Bethesda, MD: Naval Medical Research Institute.

Taylor, S. E, \& Mettee, D. (1971). When similarity breeds contempt. Journal of Personality and Social Psychology, 20, 75-81.

Wenzlaff, R. M., \& Prohaska, M. L. (1989). When misery prefers company: Depression, attributions, and responses to others' moods. Journal of Experimental Social Psychology, 25, 220-233.

Wiggins, J. S. (1979). A psychological taxonomy of trait-descriptive terms: The interpersonal domain. Journal of Personality and Social Psychology, 37, 395-412.

Wiggins, J. S. (1982). Circumplex models of interpersonal behavior in clinical psychology. In P. C. Kendall \& J. N. Butcher (Eds.), Handbook of research methods in clinical psychology (pp. 183-221). New York: Wiley.

Wiggins, J. S., Phillips, N., \& Trapnell, P. (1989). Circular reasoning about interpersonal behavior. Evidence concerning some untested assumptions underlying diagnostic classification. Journal of Personality and Social Psychology, 56, 296-305.

Winer, D. L., Bonner, T. O., Blaney, P. H. \& Murray, E. J. (1981). Depression and social attraction. Motivation and Emotion, 5, 153-166.

Received January 9, 1989

Revision received December 4, 1989

Accepted December 13, 1989 